\title{
High carrier frequency of the 35delG deafness mutation in European populations
}

\author{
Paolo Gasparini ${ }^{1}$, Raquel Rabionet ${ }^{2}$, Guido Barbujani ${ }^{3}$, Salvatore Melchionda ${ }^{1}$, \\ Michael Petersen ${ }^{8}$, Karen Brøndum-Nielsen ${ }^{4}$, Andres Metspalu ${ }^{5}$, Eneli Oitmaa ${ }^{5}$, \\ Marina Pisano ${ }^{6}$, Paolo Fortina ${ }^{7}$, Leopoldo Zelante ${ }^{1}$, Xavier Estivill ${ }^{2}$ and the \\ Genetic Analysis Consortium of GJB2 35delG
}

\begin{abstract}
${ }^{1}$ Servizio di Genetica Medica, Ospedale Casa Sollievo de la Sofrenza, San Giovanni Rotondo, Italy; ${ }^{2}$ Deafness Research Group, Centre de Genètica Mèdica i Molecular, L'H ospitalet, Barcelona, Catalonia, Spain; ${ }^{3}$ Dipartimento di Biologia, Università di Ferrara, Italy; ${ }^{4}$ D epartment of Medical Genetics, The John F Kennedy Institute, Glostrup, Denmark; ${ }^{5} \mathrm{C}$ enter of Gene Technology and Institute of M olecular and Cell Biology, University of Tartu, Estonia; ${ }^{6}$ Centro-CNR, Alghero, Sardinia, Italy; ${ }^{7}$ D epartment of Hematology, Children's Hospital of Philadel phia, Philadelphia, USA; ${ }^{8}$ D epartment of Child Health, Children's Hospital, Athens, Greece
\end{abstract}

Congenital deafness accounts for about 1 in $\mathbf{1 0 0 0}$ infants and approximately $80 \%$ of cases are inherited as an autosomal recessive trait. Recently, it has been demonstrated that connexin 26 (GJB2) gene is a major gene for congenital sensorineural deafness. A single mutation (named 35delG) was found in most recessive families and sporadic cases of congenital deafness, among Caucasoids, with relative frequencies ranging from $28 \%$ to $63 \%$. We present here the analysis of the $35 \mathrm{del}$ (G mutation in 3270 random controls from 17 European countries. We have detected a carrier frequency for 35delG of 1 in 35 in southern Europe and 1 in 79 in central and northern Europe. In addition, 35delG was detected in five out of 376 Jewish subjects of different origin, but was absent in other non-European populations. The study suggests either a single origin for 35delG somewhere in Europe or in the Middle East, and the possible presence of a carrier advantage together with a founder effect. The 35delG carrier frequency of 1 in 51 in the overall European population clearly indicates that this genetic alteration is a major mutation for autosomal recessive deafness in Caucasoids. This finding should facilitate diagnosis of congenital deafness and allow early treatment of the affected subjects. European Journal of Human Genetics (2000) 8, 19-23.

Keywords: GJB2; 35delG; carrier frequency; genetic deafness

\section{Introduction}

Congenital deafness accounts for about 1 in 1000 infants. $^{1}$ Approximately $80 \%$ of cases of congenital deafness are inherited in an autosomal recessive fashion or are apparently sporadic. ${ }^{2}$ The DFNB1 locus for non-syndromic sensorineural deafness on human chromosome $13 q 11^{3-5}$ was demonstrated to correspond to the connexin 26 (GJB2) gene in Pakistani ${ }^{6}$ and Mediterranean families, ${ }^{7,8}$ suggesting that GJB2 is a

Correspondence: Dr P Gasparini, Servizio di Genetica Medica, Ospedale Casa Sollievo de la Sofrenza, San Giovanni Rotondo, Italy. Tel: +39-0882-410825; Fax: +39-0882-411616; E-mail: GENETCSS@FG. NETTUNO.IT

Received 23 March 1999; revised 27 August 1999; accepted

2 September 1999 major gene for congenital sensorineural deafness. At least a total of 29 different mutations have been detected in the GJB2 gene, mainly in autosomal recessive and in sporadic cases of congenital deafness ${ }^{6-12}$ (http//:www.iro.es/ cx26deaf.html). Among these, 35delG is the most common mutation in patients with autosomal recessive sensorineural deafness from Australia, France, Israel, Italy, Lebanon, Morocco, New Zealand, Spain, Tunisia, UK and USA, with relative frequencies ranging from $28 \%$ to $63 \% .^{8-12}$ Mutation 35 delG has also been detected in apparently sporadic cases of deafness, accounting for $33 \%$ of deaf patients from Italy and Spain, ${ }^{8}$ and about $10 \%$ of those from Belgium and the UK. ${ }^{12}$ The overall relative frequency of the $35 \mathrm{del}$ G mutation in patients with congenital deafness (familial and sporadic) has 
been estimated at $40 \%,{ }^{8}$ a high carrier frequency considering that genetic heterogeneity has been suggested ${ }^{13}$ for congenital deafness.

Since 35delG is found in a large proportion of patients with either recessive and/or sporadic deafness, and congenital deafness accounts for about 1 in 1000 live births, we expect a large number of asymptomatic 35delG carriers in the general population. Based on the frequencies of 35del G homozygotes among Italian and Spanish patients with congenital deafness, a carrier frequency of about 1 in 30 was estimated, remarkably close to the figure ( 1 in 31 ) observed in 280 un related normal subjects. ${ }^{6}$ Here, we report the data of a large population screening that confirm the high 35delG carrier frequency in Europe.

\section{Materials and methods \\ Samples}

A total of 3931 samples from 17European countries, five different Jewish populations, plus Egyptians and North American Blacks was obtained for the analysis of the $35 \mathrm{del}$ mutation. The samples were unrelated random controls with a normal male/female sex ratio. They were sent to either Barcelona or San Giovanni Rotondo for analysis, with the exception of the samples from Denmark, Estonia, and 200 samples from Greece.

\section{Mutation analysis}

DNA was extracted from peripheral blood according to standard protocols. Samples analysed in the Barcelona laboratory and those from Sardinia (Italy) were studied by allele specific oligonucleotide hybridisation using the oligonucleotide probes and hybridisation conditions previously described. ${ }^{14}$ Samples analysed in San Giovanni Rotondo and in Estonia were studied by GENSCAN analysis after electrophoretic separation on an $\mathrm{ABI} 373$ or 377 machine as previously described. ${ }^{7}$ Two hundred samples were analysed in Greece using a modification ${ }^{15}$ of an ARMS-PCR method. Ninety-five samples were studied in Denmark by dideoxyfingerprinting with GTP as a single nucleotide.

\section{Analysis of molecular variance}

Chi-square test was used to estimate the difference of proportion, whilst Amova ${ }^{16}$ was used to partition the overall genetic diversity into three hierarchical components, representing differences between individuals within populations, among populations, and among groups, respectively.

\section{Results}

We have analysed the carrier frequency of $35 \mathrm{del}$ in 3270 unrelated random subjects of 17 European populations, in an additional sample of 376Jewish individuals of different origin, and in two other population groups (Egyptians and African-American) for an overall number of 3931 random subjects investigated. Although the highest 35delG carrier frequency was found in Estonia ( 1 in 22), the Mediterranean countries showed significantly higher carrier frequencies than northern and central European countries $\left(\chi^{2} 10.54\right.$, $P=0.002$ ). 35delG carrier frequencies in Mediterranean countries ranged between 1 in 29 and 1 in 45, with an overall carrier frequency of 1 in 35. Interestingly, the carrier frequencies of $35 \mathrm{del} \mathrm{G}$ in the Mediterranean region are higher than in the common cystic fibrosis $\Delta \mathrm{F} 508$ mutation carrier frequencies in the CFTR gene in the same area. ${ }^{17}$

Conversely, the heterozygote frequency for 35delG in central and northern Europe varied between 1 in 22 (Estonia) to 1 in 200 (France) (Table1). No carriers of 35delG were found in 119 individuals from the UK. The overall carrier frequency of mutation 35delG in these parts of Europe was 1 in 79 , about half the figure estimated for the Mediterranean region.

Mutation 35delG was also detected in 1 of 29jews of Persian origin, 1 in 50 north African Jews and 1 in 115 Iraqui Jews, but was not found in Ashkenazi Jews, Egyptians and African-Americans (Table2).

Although a lower carrier frequency for 35del G was detected in northern and central European countries compared with southern Europeans, the individual country frequencies are heterogeneously distributed. On a continental scale, the geographical pattern, described by spatial autocorrelation, ${ }^{18}$ does not depart significantly from randomness and does not indicate the presence of a gradient. This can be partly due to

Table 1 Carrier frequency of mutation 35delG in the GJB2 gene in 17 European countries

\begin{tabular}{lcll}
\hline Country & $\begin{array}{c}\text { Detected/ } \\
\text { studied }\end{array}$ & $\begin{array}{l}\text { Carrier } \\
\text { frequency }\end{array}$ & $\begin{array}{l}95 \% \\
\mathrm{Cl}\end{array}$ \\
\hline Northern and Central & $\begin{array}{c}\text { Europe } \\
\text { Denmark }\end{array}$ & $2 / 95$ & $1 / 47.5$ \\
Norway & $1 / 190$ & $1 / 190$ & \\
Estonia & $5 / 113$ & $1 / 22.5$ & \\
United Kingdom & $0 / 119$ & $0 / 119$ & \\
Germany & $4 / 200$ & $1 / 50$ & \\
Belgium & $1 / 190$ & $1 / 190$ & \\
Holland & $2 / 89$ & $1 / 44.5$ & \\
France (Brittany) & $1 / 96$ & $1 / 96$ & \\
France & $1 / 200$ & $1 / 200$ & \\
Czech Republic & $4 / 195$ & $1 / 48.7$ & \\
Slovenia & $1 / 182$ & $1 / 182$ & \\
Bulgaria & $1 / 157$ & $1 / 157$ & \\
Total & $23 / 1826$ & $1 / 79.3$ & \\
1/55-1/142 & & & \\
Southern Europe & & & \\
Portugal & $4 / 179$ & $1 / 45$ & \\
Spain & $5 / 200$ & $1 / 40$ & \\
Italy & $8 / 255$ & $1 / 32$ & \\
Italy (Sardinia) & $4 / 116$ & $1 / 29.5$ & \\
Malta & $4 / 144$ & $1 / 36$ & \\
Greece & $12 / 400$ & $1 / 33$ & \\
Turkey & $4 / 150$ & $1 / 37.5$ & $1 / 32-1 / 39$ \\
Total & $41 / 1444$ & $1 / 35.2$ & \\
Total & $64 / 3270$ & $1 / 51.1$ & $1 / 64$ \\
\hline
\end{tabular}


the large standard errors associated with the very low allele frequency estimates, but also to the high carrier frequency among Estonians, an obvious exception to the low 35delG frequencies elsewhere in northern Europe. In synthesis, spatial autocorrelation shows that, given the carrier frequency observed in one country, no statistically robust prediction can be made of the carrier frequency in neighbouring countries.

However, a form of analysis of variance (Amova) ${ }^{16}$ was able to identify some degree of geographical structuring. The largest fraction of genetic diversity in humans is represented by individual differences within populations, ${ }^{19}$ here accounting for more than $99 \%$ of the total diversity. Less than $0.1 \%$ of the total is due to differences among populations, whereas the differences among groups of populations, albeit limited in extent, reach statistical significance in five independent runs of analysis, based on five models of population structure (Table3).

Under Model 1, seven groups were considered (northern, central, eastern and southern Europe, near East, Jewish populations, and non-European samples). The inter-group component of variance appeared to be significantly greater than 0 , and it was further increased in Model 2, in which Estonians, in an evident outlier country (Figure1), were removed from the analysis. In Model 3, the five Jewish samples were grouped with their geographical neighbours. This resulted in an increased fraction of variance explained

Table 2 Carrier frequency of mutation 35delG in the GJB2 gene in other populations

\begin{tabular}{llll}
\hline Country & $\begin{array}{l}\text { Detected/ } \\
\text { studied }\end{array}$ & $\begin{array}{l}\text { Carrier } \\
\text { frequency }\end{array}$ & $\begin{array}{l}95 \% \\
\mathrm{Cl}\end{array}$ \\
\hline Persian Jews & $2 / 59$ & $1 / 29.5$ & \\
Iraqui Jews & $1 / 115$ & $1 / 115$ & - \\
Yemenite Jews & $0 / 13$ & - & - \\
Askenazi Jews United & $0 / 89$ & - & \\
North African Jews & $2 / 100$ & $1 / 50$ & \\
Total & $5 / 376$ & $1 / 75.2$ & $1 / 23-1 / 310$ \\
Arabs & $1 / 58$ & $1 / 58$ & \\
Egyptians & $0 / 95$ & - & - \\
North American Blacks & $0 / 190$ & - & - \\
\hline
\end{tabular}

Table 3 Comparison of components of genetic variance (Amova) under five models describing the population distribution of the 35delG allele. (Estonian sample removed from the analysis)

\begin{tabular}{llll}
\hline Model & $\begin{array}{l}\text { No of } \\
\text { groups }\end{array}$ & $\begin{array}{l}\text { Variance } \\
\text { between groups }\end{array}$ & $\begin{array}{l}\text { P of a more } \\
\text { extreme value }\end{array}$ \\
\hline 1 & 7 & $0.42 \%$ & 0.009 \\
2 & $7^{\text {a }}$ & $0.49 \%$ & 0.0019 \\
3 & 6 & $0.47 \%$ & 0.001 \\
4 & 3 & $0.37 \%$ & 0.009 \\
5 & $3^{\text {a }}$ & $0.50 \%$ & 40.001 \\
\hline
\end{tabular}

${ }^{a}$ Estonia excluded. by inter-group differences as compared with Model 1, showing that the Jewish populations do not differ significantly from their non-Jewish neighbours. Model 4 showed a decrease in the fraction of diversity explained by differences among groups when three such groups, namely northern, southern and non-Europeans, were considered. However, when Estonians who, like Finns, speak an Uralic non-IndoEuropean language, are removed from the analysis (Model 5), the best discrimination among groups $(P<0.001)$ was obtained. Genetic diversity in the Finn population is known to reflect a probable founder effect. ${ }^{20,21}$ A similar demographic history, characterised by some kind of founder effect whose consequences may include the increase of $35 \mathrm{del}$ allele frequency, can now also be suggested for Estonians. Once this population is excluded from the analysis, the distribution of $35 \mathrm{del}$ allele reflects a rough subdivision of Europe into two areas, central-northern to southern, with frequencies in the latter being roughly twice those in the former.

\section{Discussion}

Our data clearly demonstrate a high carrier frequency and a different geographic distribution of 35del G in central northern and southern Europe. There are several possible explanations for this finding. The high frequency of 35delG carriers suggests either a founder effect or a selective advantage for heterozygotes or a combination of both. Since GJB2 is expressed in a large number of tissues, ${ }^{22,23}$ it is possible that the putative carrier advantage is related to a function of GJB2 in one of these tissues, but clearly not the cochlea. This carrier advantage could be related to specific functions of gap junctions and be involved in climate, food, toxic factors, infectious agents, or other factors, reflecting different geographic and cultural conditions that could influence the frequency of 35delG.

The high frequency of mutation 35delG in the Caucasoid population has been attributed to the fact that the mutation occurs within a sequence of $T(G)_{6} T$, which may favour slippage and mispairing during DNA replication. ${ }^{7}$ The fact that mutation 35insG occurs in the same stretch of six guanines of $35 \mathrm{delG},{ }^{8}$ would support the view that this sequence is a hot spot for mutations and that there are several origins of the 35delG mutation. However, a mutational hot spot is expected to have two consequences, namely (i) little linkage disequilibrium between 35delG and the flanking markers, and (ii) the presence of comparable frequencies of $35 \mathrm{del}$ c carriers outside Europe. The latter does not seem to be the case. As for linkage disequilibrium, high levels thereof would suggest that the diffusion of the $35 \mathrm{del} G$ allele is due to some form of migrational process. In addition, preliminary data on haplotype analysis of Italian patients demonstrate that the majority of them carry the same haplotype, suggesting the presence of a common founder 


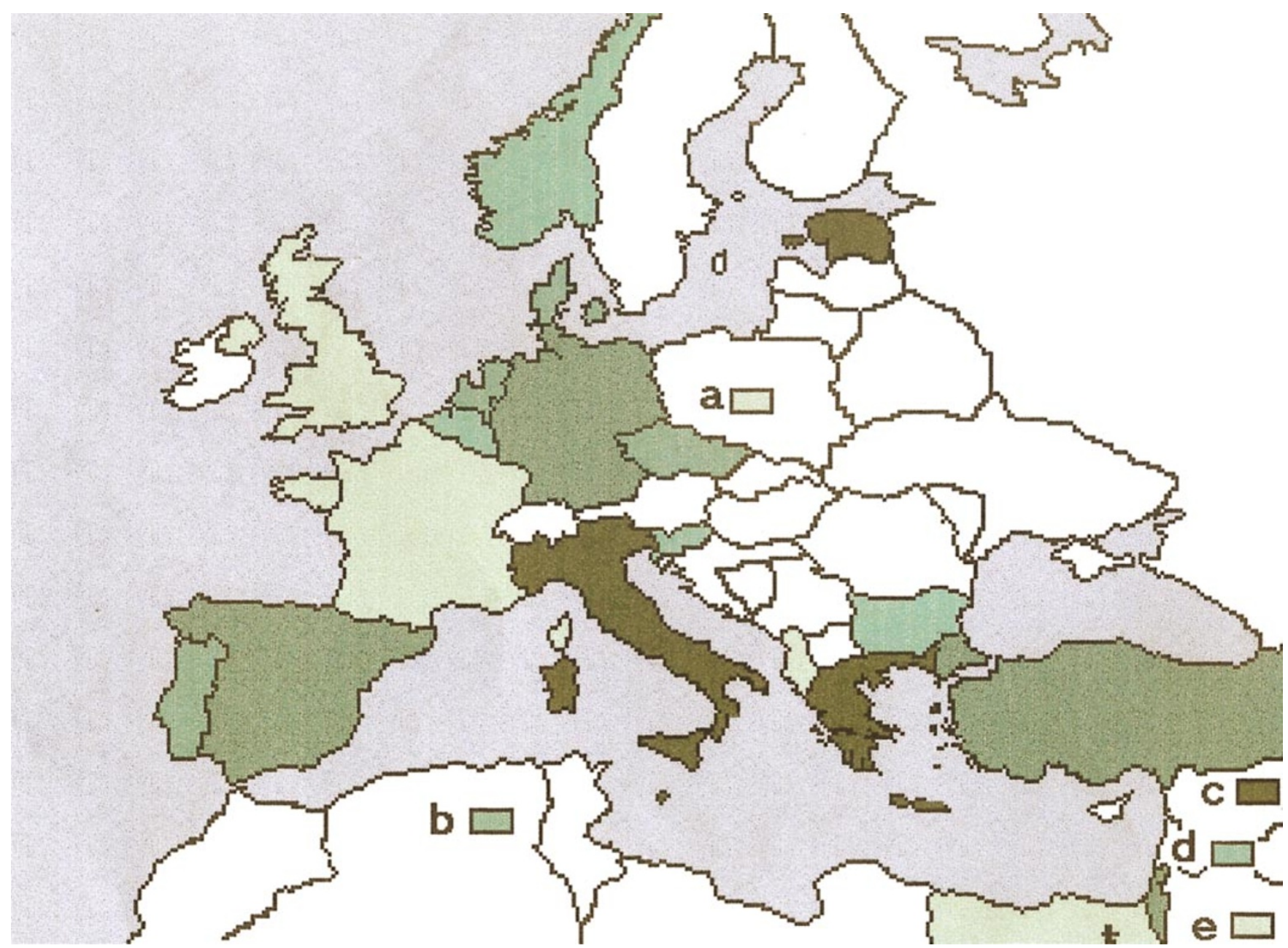

Figure 1 Estimated frequencies of the 35delG heterozygotes in several European and Mediterranean populations. Different countries have different shading corresponding to the different 35delG carrier frequencies; a darker shade corresponds to a higher carrier frequency. Rectangular insets represent Jewish populations (a: Ashkenazi; b: north African; c: Persian; d: Iraq; e: Yemenite); Arabs from Israel are mapped in Israel; independent frequencies have been estimated for France and Brittany. Populations that have not been tested are in white

(data not shown). The patterns of cancer mortality in Europe, for example, correlate with the patterns of gene flow between populations, as inferred from the historical record of population contacts. ${ }^{24}$ In any case, the absence of the $35 \mathrm{del}$ mutation outside Europe can be explained as the consequence of a single origin, somewhere in Europe or in the Middle East. The fact that the Jewish populations do not differ much from non-Jewish neighbours suggests that, after the occurrence of 35delG, sufficient gene flow has occurred to make the two communities similar. However, the sample sizes from these communities are small. Also, it would be pointless to estimate admixture rates, but the relationship observed here between the two communities seems closer than previously described. ${ }^{25}$ In a recent paper, a high carrier frequency of another GJB2 mutation has been described in
Ashkenazi Jews. ${ }^{26}$ This finding is in agreement both with the negative results we obtained for $35 \mathrm{del}$ carrier frequency in this selected Jewish population and with the major role played by GJB2 in determining deafness in Jewish populations, also here described.

In conclusion, this study shows (i) a high carrier frequency of 35del in most European countries, (ii) a higher frequency of 35delG in southern, as opposed to northern and central, Europe, and (iii) a likely single origin for 35delG, somewhere in Europe or the Middle East. The study also suggests that a carrier advantage together with a founder effect could explain the extremely high frequency of this common frameshift mutation in the GJB2 gene. This high frequency of $35 d e l G$ should facilitate diagnosis of congenital deafness and allow early treatment of the affected subjects. 


\section{Acknowledgements}

This work was supported by a grant from the Fundació La Marató de TV3 (1998). RR is supported by a grant from the Spanish Ministry of Health and Social Security (BEFI 98/9207) and XE by a grant EU BIOMED BM H4-CT 96-1364. PG is supported by a Telethon grant and by the Italian Ministry of Health. PG and RR contribute equally to this work. The Genetic Analysis Consortium of GJB2 35delG included: Gert Matthijs (Leuven, Belgium), Ivo Kremensk (Sofia, Bulgaria), Milan Macek Jr, Milan Macek Sr, Alice Krebsova (Prague, Czech Republic), Cecile Cazeneuve (Paris, France), Claude Ferec (Brest, France), M anfred Stuhrmann (Hannover, Germany), Edwin Mariman (Nijmegen, Holland), Motti Shoat, Mordechai Shohat, Nurit Magal (Petah Tikva, Israel), Andrea Novelletto (Rome, Italy), Cristina Patrosso (Milan, Italy), Dragana Josifova, AE Felice (La Valletta, Malta), Kristin Eiklid (Oslo, Norway), Paula Pachecho (Lisboa, Portugal), Damjan Glavac, Metka Glavac (Ljubljana, Slovenia), Radovan Komel, Lana Strmecki (Ljubliana, Slovenia), Asli Tolun (Istanbul, Turkey) and Martin Schwarz (Manchester, UK).

\section{References}

1 Morton NE: Genetic epidemiology of hearing impairment. Ann NY Acad Sci 1991; 630: 16-31.

2 van Camp G, Willems PJ, Smith RJH: Nonsyndromic hearing impairment: Unparalleled heterogeneity. Am J Hum Genet 1997; 60: 758-764.

3 Guilford P, Ben Arab S, Blanchard Set al: A non-syndromic form of neurosensory, recessive deafness maps to the pericentromeric region of chromosome 13q. Nat Genet 1994; 6: 24-28.

4 Brown KA, Janjua AH, Karbani G et al: Linkage studies of nonsyndromic recessive deafness (NSRD) in a family originating from the Mirpur region of Pakistan maps DFNB1 centromeric to D13S175. Hum Mol Genet 1996; 5: 169-175.

5 Gasparini P, Estivill X, Volpini V et al: Linkage of DFNB1 to nonsyndromic neurosensory autosomal recessive deafness in Mediterranean families. Eur J Hum Genet 1997; 5: 83-88.

6 Kelsell DP, Dunlop J, Stevens HP et al: Connexin 26 mutations in hereditary non-syndromic sensorineural deafness. Nature 1997; 387: 80-83.

7 Zelante L, Gasparini P, Estivill $X$ et al: Connexin 26 mutations associated with the most common form of non-syndromic neurosensory autosomal recessive deafness (DFNB1) in Mediterraneans. Hum Mol Genet 1997; 9: 1605-1609.

8 Estivill X, Fortina P, Surrey $\mathrm{S}$ et al: Connexin-26 mutations in sporadic and inherited sensorineural deafness. Lancet 1998; 351: 394-398.

9 Denoyelle F, Weil D, Maw MA et al: Prelingual deafness: high prevalence of a 30delG mutation in the connexin 26 gene. Hum Mol Genet 1997; 6: 2173-2177.
10 Kelley PM, Harris DJ, Comer BC et al: Novel mutations in the connexin 26 gene (GJB2) that cause autosomal recessive (DFNB1) hearing loss. Am J Hum Genet 1998; 62: 792-799.

11 Scott DA, Kraft ML, Carmi R et al: Identification of mutations in the connexin 26 gene that cause autosomal recessive nonsyndromic hearing loss. Hum Mutat 1998; 11: 387-394.

12 Lench N, Houseman M, Newton V, Van Camp G, Mueller R: Connexin-26 mutations in sporadic non-syndromal sensorineural deafness. Lancet 1998; 351: 415.

13 Petit C: Genes responsible for human hereditary deafness: symphony of a thousand. Nat Genet 1996; 14: 385-391.

14 Rabionet R, Estivill X: Allele specific oligonucleotide analysis (ASO) for the common mutation 35delG in the connexin 26 (GJB2) gene. J Med Genet 1999; 36: 260-261.

15 Antoniadi T et al: High prevalence in the Greek population of the 35delG mutation in the connexin 26 gene causing prelingual deafness. Clin Genet 1999; 55: 381-382.

16 Excoffier L, Smouse PE, Quattro J: Analysis of molecular variance inferred from metric distances among haplotypes: Application to human mitochondrial DNA restriction data. Genetics 1992; 131: 479-491.

17 Morral N, Bertranpetit J, Estivill $X$ et al: The origin of the major cystic fibrosis mutation $(\Delta \mathrm{F} 508)$ in European populations. Nat Genet 1994; 7: 169-175.

18 Sokal RR, Oden NL: Spatial autocorrelation in biology. 1. Methodology. Biol J Linn Soc 1978; 10: 199-228.

19 Barbujani G, Magagni A, Minch E, Cavalli-Sforza L: An apportionment of human DNA diversity. Proc Natl Acad Sci USA 1997; 94 4516-4519.

20 De La Chapelle A: Disease gene mapping in isolated human populations: The example of Finland. J Med Genet 1993; 30 : 857-865.

21 Laan M, Pääbo S: Demographic history and linkage disequilibrium in human populations. Nat Genet 1997; 17: 435-438.

22 Ichimiya I, Adams JC, Kimura RS: Changes in immunostaining of cochleas with experimentally induced endolymphatic hydrops. Ann Otol Rhinol Laryngol 1994; 103: 457-468.

23 Kikuchi T, Kimura RS, Paul DL, Adams J: Gap junctions in the rat cochlea: immunohistochemical and ultrastructural analysis. Anat Embryol 1995; 191: 101-118.

24 Livshits G, Sokal RR, Kobyliansky E: Genetic affinities of Jewish populations. Am J Hum Genet 1991; 49: 131-146.

25 Sokal RR, Oden NL, Rosenberg MS, DiGiovanni D: Ethnohistory, genetics, and cancer mortality in Europeans. Proc Natl Acad Sci USA 1997; 94: 12728-12731.

26 Morell RJ et al: Mutations in the connexin 26 gene among Ashkenazi Jews with nonsyndromic recessive deafness. N Engl ] Med 1998; 19: 1545-1547. 